\title{
Reflections on Political Ecology of Mount Cameroon's Prunus Africana
}

\author{
Ayonghe Akonwi Nebasifu \\ PhD Researcher of Sociology \\ (Anthropology Research Group, Arctic Centre) \\ University of Lapland, Finland
}

\begin{abstract}
This paper written for World-Ecology Research Network Conference at University of Helsinki, August 2018, reflects upon developments in capitalism of Prunus Africana within a theoretical framework of co-management critique. On the case of Mount Cameroon in Sub-Saharan West Africa, I argue processes of commercialization and socio-economic repercussions surrounding Prunus Africana: a plant that serves for treatment of prostatic diseases - interwoven with bureaucratic initiatives of sustainable management. By reviewing published literature, I argue the involvement of stakeholders in capitalist arrangements from the $1990 \mathrm{~s}$ to periods following the establishment of Mount Cameroon National Park - significantly scrutinized by Convention on International Trade in Endangered Species (CITES), European Commission, and the International Union for Conservation of Nature (IUCN). Major actors include Mount Cameroon Prunus Management Company (MOCAP) endorsed by the state; state subsidiaries Cameroon Development Corporation (CDC) and Limbe Botanic Garden (LBG); collaborate buyers - Plantecam and Afriquia Medicament (AFRIMED); and Prunus Africana Harvesters' Unions in nearby villages. Analysis demonstrate benefits in sustainable harvesting of Prunus, whilst raising ontological concerns of resource-appropriation, elite control, unsatisfactory labour wages, and vulnerabilities of traditional ecological knowledge to commercialization.
\end{abstract}

Keywords: Political Ecology, Capitalism, Prunus Africana, Mount Cameroon

\section{INTRODUCTION}

Where natural resources locate near communities, dynamics of extraction is of relevant discourse in a context of medicinal plants. [9] highlighted that, according to World Health Organization (WHO), 80\% of world population rely on traditional medicine of which $85 \%$ pertains to plants. This perpetuates global dependence on sustainable management to meet market demand and supply. A typical example is the Prunus Africana plant in Cameroon: once the biggest global exporter of Prunus Africana (UNEP WCMC, 2008). On Mount Cameroon, Prunus grows up to 30 meters in height and a diameter of about 1.5 meters, in altitudes between 700 to 3000 meters of the montane forest [9]. Extract from Prunus bark is of medicinal value not just for local communities, but also to Western communities as a treatment for prostatic hyperplasia, malaria, stomach-pain, and fever. Before 1970s, Bakweri people of Mount Cameroon for many years extracted Prunus traditionally for medicinal need.

However, following 1970s, intensified exports in trade endangered Prunus on Mount Cameroon, stimulating IUCN categorize Prunus as vulnerable species. This equally impelled CITES assigning quota for Prunus extraction extended to 2006 [3]. CITES further suspended Cameroon from exportation of Prunus in 2006. Still, in 2007, the European Commission (EC) banned imports of Prunus from Cameroon. In 2009, Mount Cameroon National Park (MCNP) was created, and in 2010, CITES uplifted all quotas. Since 2009, Mount Cameroon Prunus 
Management Company Ltd. (MOCAP) was in charge of sustainable management of Prunus on Mount Cameroon. By 2009, a participatory approach of capitalism had emerged constituting three commercial actors: state induced company MOCAP; state subsidiaries Cameroon Development Corporation (CDC) and Limbe Botanic Garden (LBG); collaborate buyer Afriquia Medicament (AFRIMED); and Prunus Africana Harvesters' Unions in nearby villages [4, 2, 5]. Socio-economic significances of these processes vary - ranging from income benefits to imbalanced compensations. In this paper, I shall elaborate on capitalist initiatives, various implications, while suggesting a way forward for the sustainable extraction of Prunus.

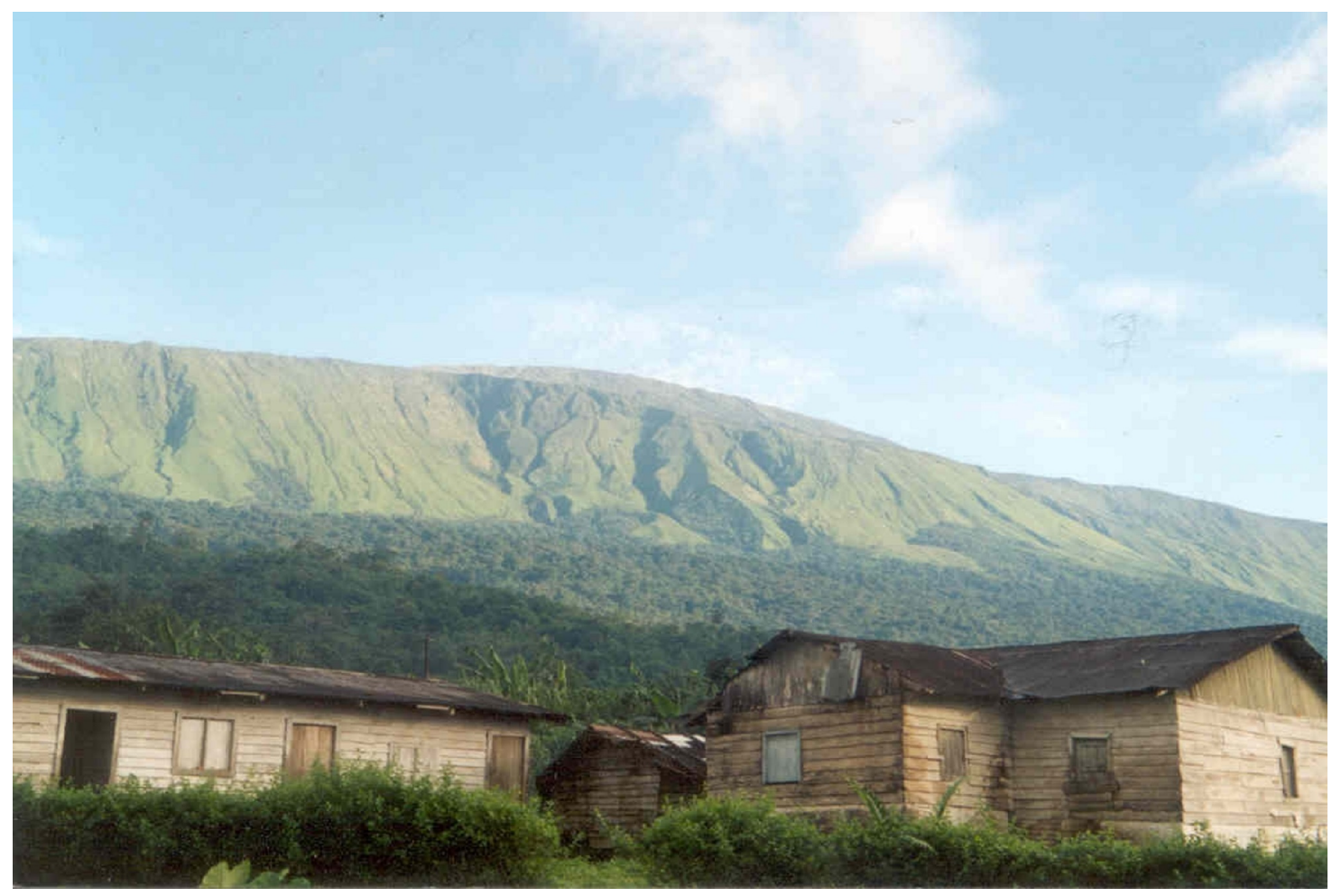

Figure 1: Mount Cameroon (Bellewang, 2006: 30)

THEORETICAL FRAMING

Co-management theory examines collaboration between stakeholders and local community. Two writings are of interest, [6] and [8]. [6] addresses co-management of natural resources from a standpoint of sharing power. Here, a distinction occurs between social progress and destructive change i.e. implementing co-management activities by means of force without careful assessment of slow progress and its benefits - depicted by local communities alienated from natural resources, and lack of trust on bureaucratic regimes. Causal to such ambiguity is what [8] argued as difficulties in integrating Science with traditional knowledge. In Nadasdy's study of Ruby Range Sheep Steering Committee (RRSSC) in Southwest Yukon Canada, he found that efforts by Yukon government biologists, to limit sheep hunting resulted to legitimization of biologists' position in decision making at detriment of first nation Kluane elders and hunters. An outcome attributed to disagreement and ignorance on the part of government biologists to include Kluane proposals in final plans for management of Ruby Range Sheep - what I call ineffective participation.

\section{REVIEW OF LITERATURE}

Several studies are relevant for this section. For instance, [5] identified MOCAP as a stakeholder in co-management of Prunus on MCNP - by effective introduction of new management schemes in 2009, following suspension of local Pharmaceutical company, Plantecam. MOCAP provides (and sells) seedlings of Prunus to collaborate communities for 
cultivation, deals directly with a buyer AFRIMED, and shares Prunus revenues with partner communities. [9] examined Production-to-Consumption Systems (PCS) of Prunus on Mount Cameroon. This report showed that between 1994 and 2000, Mount Cameroon Project engaged 500 farmers in cultivation of Prunus in the area. In addition, while Cameroon Development Corporation (CDC) established 9 hectares with 10000 Prunus planted, some 20 000 seedlings were made available for planting at Limbe Botanic Garden and Plantecam nurseries. Furthermore, government lands constituted $90 \%$ of Prunus in the year 2000. In 2008, a report [9] identified Cameroon as the largest global exporter of Prunus.

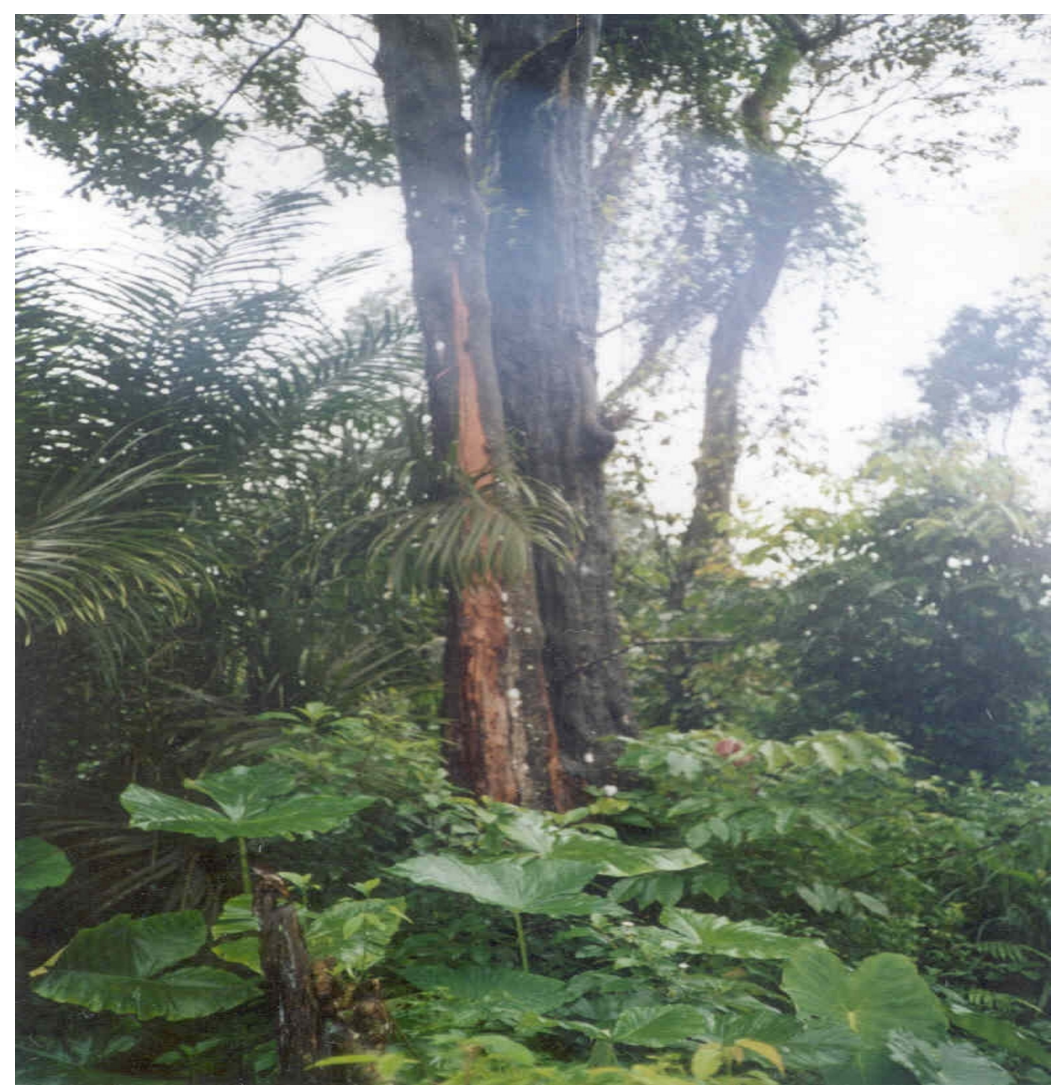

Figure 2: Freshly debarked Prunus Africana tree, Bokwaongo Forest [2]

Although Betti et al [3] indicated an estimate of 79660 Prunus trees on Mount Cameroon, a preliminary report by [1] showed that inside MCNP, Prunus had its highest density of 34885 exploitable trees, and 6157 outside MCNP. In terms of annual quota estimates for Prunus extraction, a total of 205.21 tons recorded, of which 174.42 tons a year inside MCNP, and 30.7 tons a year outside MCNP. Hence, the importance of protected area in sustaining Prunus is crucial for the Mount Cameroon area. [2] analysed socio-economic impact of Prunus management on Mount Cameroon targeting a case of Bokwaongo Prunus Africana Harvesters' Union: an initiative introduced in collaboration with MCNP management authorities. Findings showed that members of the union gained employment, financial security, and promoted sharing of benefits among members. Amidst Prunus management, critiques [4, 7] argued the adverse effects of commercialization, regarding significant revenues made by capitalists at detriment of local harvesters.

\section{METHODOLOGY}

I reviewed published materials about Prunus management on Mount Cameroon. These were then analysed using discourse analysis. My objective seeks to highlight processes of capitalism in Prunus Africana trade and elaborate on possible implications for local communities around Mount Cameroon. Specifically, my questions are; how has the commercialization of Prunus 
Africana evolved between 1970s to present? What measures promote sustainable Prunus extraction? Are there any benefits or setbacks? If so, what possible remedies are suitable for improvements?

\section{RESULTS AND ANALYSIS}

Historical narratives about commercializing Prunus Africana in Africa associates with 1960s visit of a German medical doctor, in Kwazulu Natal, South Africa [4]. By watching Zulu men use Prunus to treat difficulties of urinating, he then encouraged a search for potential wider use of Prunus in Africa to treat Benign Prostatic Hypertrophy. In Cameroon, Western demand for Prunus increased significantly after 1970s leading to intensified exports [4]. Between 1990s and 2008, Plantecam and an Industrial company (SESPO SARL) were prominent buyers of Prunus - though replaced in 2009 with the coming of MOCAP's responsibility for managing Prunus on MCNP, and the rise of new buyer AFRIMED. These were part of wider state initiatives to ensure sustainable Prunus management [5]. Moreover, following 1990s, a Mount Cameroon Project included CDC and LBG into Prunus diversification through plantation agriculture and Prunus nurseries [9]. The period 2000s witnessed the rise of Prunus Harvesters Unions in many villages [1]. By 2008, an EU report highlighted Cameroon as the largest global exporter of Prunus, with France and Spain as dominant markets [10].

Attempts to ensure sustainable extraction of Prunus pertains to eras 1990s, 2000s, and 2009. Firstly, use of sanctions and quotas, in response to uncontrolled harvesting of Prunus. These measures include IUCN's classification of Prunus as vulnerable species and CITES' imposition of a quota for Prunus extraction (minimum diameter of $30 \mathrm{~cm}$ ) and exploitation (maximum of 2000 tons per year for its dried barks) in 1990s. Also, Cameroon's suspension by CITES in 2006 from exporting Prunus due to allegations of unsustainable harvesting by Plantecam, EU banned imports of Prunus from Cameroon in 2007 [4]. From 2005 onwards, villages of Mount Cameroon began to have harvesters unions that enhance benefit sharing [1], which increased after 2009. Lastly, designation of Mount Cameroon as a protected area in 2009 coupled with the placing MOCAP in charge of Prunus management facilitated Prunus growth.

Thus, Mount Cameroon sub-divided into five blocks of Prunus, harvested on a rotational interval of five years. MOCAP signed a memorandum of understanding with partner villages of MCNP that led to training of villagers as harvesters. Harvesting occurs all year round accounting for an average of $15500 \mathrm{~kg}$ (15.5 tons) in a single sale and an average revenue of 5425000 FCFA [5]. Consequently, a capitalist system of commercializing Prunus extraction comprises participation between three entities - Cameroon's government through a representative arm MOCAP, responsible for Prunus management on Mount Cameroon. Secondly, Pharmaceutical and Industrial companies (previously Plantecam and SESPO SARL) with AFRIMED being the current sole buyer of Prunus from MOCAP. Additionally, state subsidiaries like CDC and LBG promoting sustainable growth of Prunus on hectares of land out of Mount Cameroon. Lastly, Village Harvesters' Unions formed by local communities. Each of these actors benefit in one way or the other.

\section{DISCUSSION}

Socio-economic implications of capitalism in the extraction of Prunus on Mount Cameroon vary greatly on viewpoints. For instance, the state allegedly gains an annual average revenue of 65100000 FCFA from selling 188 tons of Prunus [5]. While significant revenues generate from trading between state organizations, pharmaceutical, and industrial companies, there are equally benefits to local communities -with revenue partly utilized in fostering community development. However, observations of this kind appear limited to villages with Prunus African Harvesters' Unions. Bellewang's study [1] of Bokwaongo's Prunus harvesters' union showed 
that earnings from Prunus facilitated purchasing of drugs for healthcare, and union members often gained education on sustainable methods of Prunus extraction through capacity building workshops organised by the government. In addition, most members spoke of their ability to sponsor kids at school using income from Prunus activities.

Whilst youths in the union mentioned employment gained from Prunus schemes, there are gains in financial security, as most members are encouraged to open bank accounts for savings. Another issue is the emergence of transparency in equitable benefit sharing, as oppose to dubious transactions and conflicts with intermediaries that existed years before creation of unions. In contrast, critics show setbacks of capitalism in Prunus Africana extraction. [4] argued that hopes of any decentralized governance of Prunus, were undermined by elite capture and market monopolies. This viewpoint mirrors the idea that in 2012, Cameroon allegedly made above US\$3.9 million from a Prunus bark quota of 658.675 tons, of which most went to a single company. Furthermore, 48 harvesters in MCNP received below US $\$ 1$ per day of harvest, attributed to a net bark price of US $\$ 0.33$ per kilogram [4]. Similarly, the exposure of traditional knowledge on medicinal plants, by means of discriminate commercialization. This widens criticisms on capitalism for its tendency to alienate local communities through commercial exploitation and discriminate compensation [7].

\section{CONCLUSION}

I examined capitalism in the ecology and extraction of Prunus Africana on Mount Cameroon using a review of published material. Four issues were analysed including the historical basis for capitalism in Prunus Africana trade, influenced by western demands. i then illustrated measures adopted for sustainable extraction of Prunus on Mount Cameroon. Particularly, this constituted regulatory measures imposed by CITES, EC, and Cameroon government between 1990s and 2008 - aimed at restoring populations of Prunus. Results identified three groups of actors involved in the entire capitalist arrangement. This includes government arm (MOCAP) in charge of managing Prunus on Mount Cameroon, pharmaceutical and industrial companies that buy Prunus from the state. In addition, the role of state subsidiaries CDC and LBG in diversification of Prunus, and the development of Prunus Africana Harvesters' Unions in villages.

My analysis show socio-economic impacts of capitalist arrangements to local communities. For instance, transparency brought by accountability in unions and reduction in conflicts with intermediaries. Other benefits include; income security, education, and healthcare supplies. Amid these advantages, criticisms arise from ambiguities of elites legitimizing market monopoly, and fears of minimal decentralized governance of Prunus. Other worries include chances for commercial operators exploiting traditional knowledge without fair compensation to local people. This suggests that, amid industrial initiatives for sustaining Prunus production, there is need for effective participation - achievable by legalizing on-farm production among local farmers, and improving upon compensation mechanisms with better labour wages for local harvesters that rely on Prunus schemes for employment.

\section{References}

Akoa, A., Betti, J., Ewusi, N., Mbarga, N., Akagou, Z., Fonkoua, C., Mala, A., Nkouna, A. 2011. "Preliminary Report on Sustainable harvesting of Prunus Africana (Rosaceae) in the Mount Cameroon." Preliminary report, National Forestry Development Agency (ANAFOR), the Cameroon CITES Scientific Authority for flora. August 1, 2011. http://www.itto.int/files/user/cites/cameroon/NDF_Prunus_ANAFOR_North\%20west_Cameroon_c.pdf

Bellewang, E. N. 2006. "Socio-economic impact of Prunus Africana management in the Mount Cameroon region. A case study of the Bokwoango community." Master of Science Thesis, Royal Institute of Technology, Sweden. 
Betti, J. L., Belinga, S. J., Samba, D. 2011. "Stock of Prunus Africana stems on the Mount Cameroon forest." African Journal of Plant Science 5(13): 781-789.

Cunningham, A., Anoncho, V.F., Sunderland, T. 2016. "Power, Policy and the Prunus Africana Bark Trade, 19722015." Journal of Ethnopharmacology 178 (2016): 323-333.

Fon, F. 2013. "An Analysis of Co-Management on the Development and Preservation of Natural Resources on the Mount Cameroon National Park.” Internship Report, Garoua Wildlife College, Cameroon.

Borrini-Feyerabend, G., Pimbert, M., Farvar, T., Kothari, A., and Renard, Y. 2004. Sharing Power. Learning by doing in co-management of natural resources throughout the world. IIED and IUCN/ CEESP/ CMWG, CENESTA, Tehran. https://cmsdata.iucn.org/downloads/sharing_power.pdf

Masango, C. 2013. "Traditional Knowledge and Traditional Cultural Expressions Protections: Prospects in Cameroon." Information Development 30(2): 121-129. SAGE

Nadasdy, P. 2003. "Revaluating the Co-management Success Theory." Arctic 56 (4): 367-380.

Ndam, N., Ewusi, B., Acworth, J., Tonye, M., Pouakouyou, D., Nkuinkeu, R., Dibobe, H. 2000. "Prunus Africana on Mount Cameroon. A case study of the Production-To-Consumption Systems." One of the 45 case studies commissioned by CIFOR - Centre for International Forestry Research for comparisons, Yaounde, Cameroon, 8-11 May, 2000 .

UNEP World Conservation Monitoring Centre. 2008. "Review of Prunus Africana from Cameroon." European Commission Directorate General, UNEP World Conservation Monitoring Centre, Cambridge, UK, August 2008. 